\title{
Editorial: Problematic Internet Technology Use: Assessment, Risk Factors, Comorbidity, Adverse Consequences and Intervention
}

\author{
Jon D. Elhai ${ }^{1,2 *}$, Dmitri Rozgonjuk ${ }^{3,4}$ and Julia Brailovskaia ${ }^{5}$ \\ ${ }^{1}$ Department of Psychology, University of Toledo, Toledo, OH, United States, ${ }^{2}$ Department of Psychiatry, University of Toledo, \\ Toledo, OH, United States, ${ }^{3}$ Department of Molecular Psychology, Institute of Psychology and Education, Ulm University, \\ UIm, Germany, ${ }^{4}$ Institute of Mathematics and Statistics, University of Tartu, Tartu, Estonia, ${ }^{5}$ Mental Health Research and \\ Treatment Center, Department of Clinical Psychology and Psychotherapy, Ruhr-Universität Bochum, Bochum, Germany
}

Keywords: internet addiction, smartphone addiction, problematic internet behavior, mental health, smartphone

\section{Editorial on the Research Topic}

Problematic Internet Technology Use: Assessment, Risk Factors, Comorbidity, Adverse Consequences and Intervention

There is no doubt that many personal and societal advantages are associated with using Internet technology such as social networking sites (SNS), gaming, and smartphones. For instance, smartphones have enhanced productivity in workplace (1) and educational (2) settings, and

OPEN ACCESS

Edited and reviewed by: Maximilian Pilhatsch,

Technical University of Dresden, Germany

*Correspondence: Jon D. Elhai contact@jon-elhai.com

Specialty section: This article was submitted to Addictive Disorders, a section of the journal Frontiers in Psychiatry

Received: 29 September 2021 Accepted: 01 October 2021 Published: 22 October 2021

Citation:

Elhai JD, Rozgonjuk D and Brailovskaia J (2021) Editorial: Problematic Internet Technology Use:

Assessment, Risk Factors, Comorbidity, Adverse Consequences and Intervention.

Front. Psychiatry 12:786019. doi: 10.3389/fpsyt.2021.786019 can facilitate health and mental health treatment with apps designed to complement traditional interventions (3). Furthermore, using SNS can boost social capital $(4,5)$, which can in turn promote mental health $(6,7)$. Such advantages of Internet technology use are relevant when such use is of mild to moderate frequency, conducted in healthy and adaptive ways. However, Internet technology is a double-edged sword, and can alternatively be used in unhealthy, maladaptive ways $(8,9)$.

In the current Research Topic, we address when Internet technology is used in ways that are problematic or excessive, causing dysfunction in daily life. Problematic use of Internet technology is influenced by risk factors such as mental health symptoms (10-12) which drive such problematic use in an effort to alleviate negative affect $(13,14)$. Additional risk factors for problematic Internet use involve predispositional characteristics such as personality, genetics and other biological factors, deep seated cognitions (14-16), as well as cognitive and affective responses and dysfunctional coping processes $(17,18)$. In fact, theoretical models have been developed and supported that discuss how this variety of risk factors may contribute to problematic Internet use (19). Furthermore, consequences of problematic Internet use include physical pain in the hands and neck $(20,21)$, pedestrian and driving collisions (22), distraction and poor performance in school and work (23-25), and can involve cyberbullying (26), problematic pornography use (27), and internet radicalization (28).

In the present Research Topic, authors present research in several domains related to problematic Internet use. Several papers report the development and/or validation of scales used to measure aspects of problematic Internet use-including problematic use symptoms [(29), Paschke et al.] and distractions from the smartphone (Throuvala et al.). These papers also report how these scales are related to external constructs such as mental health symptoms. For instance, Burkauskas et al. discovered that the nine-item Problematic Internet Use Questionnaire was valid in a sample of Lithuanian residents, and correlated positively with mental health symptom severity. 
Paschke et al. found that their newly developed Social Media Use Disorder Scale for Adolescents correlated positively with severity of depression and stress in German adolescents. And Throuvala et al. discovered that their newly developed Smartphone Distraction Scale correlated positively with emotional dysregulation and problematic SNS use in a sample of British university students. Such studies are important in providing researchers and clinicians with valid assessment instruments for measuring problematic Internet use and its consequences.

Other authors in this Research Topic examined stress and anxiety as potential risk factors for the problematic use of Internet technology (Yang et al.; Li et al.; Zhao and Zhao). These papers also importantly examine potential mediators or moderators (mechanisms) that can explain how stress or anxiety are related to problematic Internet use, including the fear of missing out (FOMO) on rewarding experiences (Yang et al.), self-efficacy (Li et al.), and active SNS use or SNS flow (Zhao and Zhao). Examining such mechanisms is important because psychopathology alone may not adequately explain the development or maintenance of problematic Internet use (14, 15). For example, Yang et al. revealed that FOMO mediated relations between stress and problematic smartphone use severity in a sample of Chinese university students. Li et al. found support for self-efficacy in partially mediating associations between anxiety and problematic smartphone use symptoms in a sample of Chinese college students. And Zhao and Zhao discovered that active SNS use and SNS flow mediated relations between stress about COVID-19 and problematic SNS use in Chinese college students. We believe that future research should continue to prioritize testing of moderators and mediators that explain associations between both stress and anxiety with problematic Internet use.

Other papers examine additional risk factors for problematic Internet use. Guo et al. sampled Chinese residents using a population-based survey, and examined how using different features of the smartphone may relate not only to problematic use but also to its different facets. Schivinski et al., Zhang et al., and Heng et al. examined social-related variables in

\section{REFERENCES}

1. Doargajudhur MS, Dell P. The effect of bring your own device (BYOD) adoption on work performance and motivation. J Comput Inform Syst. (2020) 60:518-29. doi: 10.1080/08874417.2018.1543001

2. Crompton H, Burke D. The use of mobile learning in higher education: a systematic review. Comput Educ. (2018) 123:5364. doi: 10.1016/j.compedu.2018.04.007

3. Huckvale K, Nicholas J, Torous J, Larsen M. Smartphone apps for the treatment of mental health conditions: status and considerations. Curr Opin Psychol. (2020) 36:65-70. doi: 10.1016/j.copsyc.2020.04.008

4. Choi S. The roles of media capabilities of smartphone-based SNS in developing social capital. Behav Inf Technol. (2018) 38:609-20. doi: 10.1080/0144929X.2018.1546903

5. Cheng C, Wang HY, Sigerson L, Chau CL. Do the socially rich get richer? A nuanced perspective on social network site use and online social capital accrual. Psychol Bull. (2019) 145:734-64. doi: 10.1037/bul0000198 association with problematic Internet use. Specifically, Schivinski et al. used an English-speaking sample of SNS users, finding that particular social motives (especially intrapersonal) were related to problematic SNS use severity. Heng et al. used a Chinese sample of undergraduates, discovering that social capital mediated relations between within-game social interactions and problematic gaming. And Zhang et al. sampled participants from China and Germany, finding that autistic traits were related to problematic Internet use. Finally, Luo et al. sampled Chinese college students, finding that adaptability regarding emotions, homesickness, and learning were related to perceived distress from losing smartphone access (or nomophobia). Studying such risk factors as social-related variables, autistic traits, and adaptability are important in furthering our understanding of why some people excessively engage in Internet use.

Finally, we mention the important commentary by Montag and Hegelich. The authors present a compelling argument that an important determinant of problematic SNS use is the way in which SNSs were developed and operate financially. That is, it is the intention of SNSs to prolong users' SNS use in order to use their data and profit from it. The authors also discuss significant societal adverse effects from the SNS business model, including problematic use, privacy infringement, and impingement on democracy through the spread of fake news.

To conclude, the present Research Topic provides readers with recent cross-national findings considering the assessment of different forms of problematic Internet technology use, and the complex mechanisms underlying the association between problematic Internet technology use and mental health that involve different inter- and intrapersonal as well as environmental and societal factors. The works published in this Research Topic contribute to the understanding of Internet technology use associations with daily-life adversities and may be useful for professionals working in this line of research.

\section{AUTHOR CONTRIBUTIONS}

All authors wrote and edited this paper.

6. Santini ZI, Koyanagi A, Tyrovolas S, Mason C, Haro JM. The association between social relationships and depression: a systematic review. J Affect Disord. (2015) 175:53-65. doi: 10.1016/j.jad.2014.12.049

7. Nabi RL, Prestin A, So J. Facebook friends with (health) benefits? Exploring social network site use and perceptions of social support, stress, and well-being. Cyberpsychol Behav Soc Netw. (2013) 16:7217. doi: 10.1089/cyber.2012.0521

8. Hussain Z, Starcevic V. Problematic social networking site use: a brief review of recent research methods and the way forward. Curr Opin Psychol. (2020) 36:89-95. doi: 10.1016/j.copsyc.2020.05.007

9. Kircaburun K, Pontes H, Stavropoulos V, Griffiths M. A brief psychological overview of disordered gaming. Curr Opin Psychol. (2020) 36:38-43. doi: 10.1016/j.copsyc.2020.03.004

10. Elhai JD, Levine JC, Hall BJ. The relationship between anxiety symptom severity and problematic smartphone use: a review of the literature and conceptual frameworks. J Anxiety Disord. (2019) 62:45-52. doi: 10.1016/j.janxdis.2018.11.005 
11. Király O, Griffiths MD, Demetrovics Z. Internet gaming disorder and the DSM-5: conceptualization, debates, and controversies. Curr Addict Rep. (2015) 2:254-62. doi: 10.1007/s40429-015-0066-7

12. Marino C, Gini G, Vieno A, Spada MM. The associations between problematic Facebook use, psychological distress and well-being among adolescents and young adults: a systematic review and meta-analysis. J Affect Disord. (2018) 226:274-81. doi: 10.1016/j.jad.2017.10.007

13. Kardefelt-Winther D. A conceptual and methodological critique of internet addiction research: towards a model of compensatory internet use. Comput Human Behav. (2014) 31:351-4. doi: 10.1016/j.chb.2013.10.059

14. Brand $\mathrm{M}$, Young $\mathrm{KS}$, Laier $\mathrm{C}$, Wolfling $\mathrm{K}$, Potenza MN. Integrating psychological and neurobiological considerations regarding the development and maintenance of specific Internet-use disorders: an Interaction of PersonAffect-Cognition-Execution (I-PACE) model. Neurosci Biobehav Rev. (2016) 71:252-66. doi: 10.1016/j.neubiorev.2016.08.033

15. Brand M, Wegmann E, Stark R, Muller A, Wolfling K, Robbins TW, et al. The Interaction of Person-Affect-Cognition-Execution (IPACE) model for addictive behaviors: update, generalization to addictive behaviors beyond internet-use disorders, and specification of the process character of addictive behaviors. Neurosci Biobehav Rev. (2019) 104:110. doi: 10.1016/j.neubiorev.2019.06.032

16. Brailovskaia J, Teichert T. "I like it" and "I need it": relationship between implicit associations, flow, and addictive social media use. Comput Human Behav. (2020) 113:106509. doi: 10.1016/j.chb.2020.106509

17. Elhai JD, Yang H, Montag C. Cognitive- and emotion-related dysfunctional coping processes: transdiagnostic mechanisms explaining depression and anxiety's relations with problematic smartphone use. Curr Addict Rep. (2019) 6:410-7. doi: 10.1007/s40429-019-00260-4

18. Yu L, Cao X, Liu Z, Wang J. Excessive social media use at work: exploring the effects of social media overload on job performance. Inform Technol People. (2018) 31:1091-112. doi: 10.1108/ITP-10-2016-0237

19. Brand M, Laier C, Young KS. Internet addiction: coping styles, expectancies, and treatment implications. Front Psychol. (2014) 5:1256. doi: 10.3389/fpsyg.2014.01256

20. Xie Y, Szeto GP Dai J, Madeleine P. A comparison of muscle activity in using touchscreen smartphone among young people with and without chronic neck-shoulder pain. Ergonomics. (2016) 59:61-72. doi: 10.1080/00140139.2015.1056237

21. Yang G, Cao J, Li Y, Cheng P, Liu B, Hao Z, et al. Association between internet addiction and the risk of musculoskeletal pain in Chinese college freshmen - a cross-sectional study. Front Psychol. (2019) 10:1959. doi: 10.3389/fpsyg.2019.01959

22. Kita E, Luria G. The mediating role of smartphone addiction on the relationship between personality and young drivers' smartphone use while driving. Transport Res F Traffic Psychol Behav. (2018) 59:20311. doi: 10.1016/j.trf.2018.09.001
23. Grant JE, Lust K, Chamberlain SR. Problematic smartphone use associated with greater alcohol consumption, mental health issues, poorer academic performance, and impulsivity. J Behav Addict. (2019) 8:335-42. doi: 10.1556/2006.8.2019.32

24. Nayak JK. Relationship among smartphone usage, addiction, academic performance and the moderating role of gender: a study of higher education students in India. Comput Educ. (2018) 123:164-73. doi: 10.1016/j.compedu.2018.05.007

25. Zivnuska S, Carlson JR, Carlson DS, Harris RB, Harris KJ. Social media addiction and social media reactions: the implications for job performance. J Soc Psychol. (2019) 159:746-60. doi: 10.1080/00224545.2019.1578725

26. Camerini A-L, Marciano L, Carrara A, Schulz PJ. Cyberbullying perpetration and victimization among children and adolescents: a systematic review of longitudinal studies. Telemat Informat. (2020) 49:101362. doi: 10.1016/j.tele.2020.101362

27. Stark R, Klucken T, Potenza MN, Brand M, Strahler J. A current understanding of the behavioral neuroscience of compulsive sexual behavior disorder and problematic Pornography use. Curr Behav Neurosci Rep. (2018) 5:218-31. doi: 10.1007/s40473-018-0162-9

28. Frissen T. Internet, the great radicalizer? Exploring relationships between seeking for online extremist materials and cognitive radicalization in young adults. Comput Human Behav. (2021) 114:106549. doi: 10.1016/j.chb.2020.106549

29. Burkauskas J, Kiraly O, Demetrovics Z, Podlipskyte A, Steibliene V. Psychometric properties of the nine-item Problematic Internet Use Questionnaire (PIUQ-9) in a Lithuanian sample of students. Front Psychiatry. (2020) 11:565769. doi: 10.3389/fpsyt.2020.565769

Conflict of Interest: The authors declare that the research was conducted in the absence of any commercial or financial relationships that could be construed as a potential conflict of interest.

Publisher's Note: All claims expressed in this article are solely those of the authors and do not necessarily represent those of their affiliated organizations, or those of the publisher, the editors and the reviewers. Any product that may be evaluated in this article, or claim that may be made by its manufacturer, is not guaranteed or endorsed by the publisher.

Copyright (C) 2021 Elhai, Rozgonjuk and Brailovskaia. This is an open-access article distributed under the terms of the Creative Commons Attribution License (CC BY). The use, distribution or reproduction in other forums is permitted, provided the original author(s) and the copyright owner(s) are credited and that the original publication in this journal is cited, in accordance with accepted academic practice. No use, distribution or reproduction is permitted which does not comply with these terms. 